\title{
Physico-Chemical Composition and Functional Properties of Blended Flour Obtained from Lentil, Pumpkin and Barley for Development of Extrudates
}

\author{
Jabeen A*, Hassan S, Masoodi L, Ajaz N and Rafiq A
}

Division of Food Technology, Islamic University of Science and Technology, Awantipora, India

\begin{abstract}
Barley based extruded snacks containing pumpkin and lentil was produced using twin screw extruder. Response surface methodology were used to optimize and evaluate the effect of three independent variables viz. feed composition $(50 \%$ to $90 \%$ barley flour; $2.5 \%$ to $42.5 \%$ lentil flour and $7.5 \%$ pumpkin flour), moisture content $(13 \%$ to $21 \%)$ and barrel temperature $\left(115^{\circ} \mathrm{C}\right.$ to $155^{\circ} \mathrm{C}$ ) on lateral expansion, bulk density, water absorption index, water solubility index, SME and breaking strength of extrudates. Low barrel temperature and low moisture content were found to enhance the lateral expansion (37-70.8) whereas low barley content significantly reduced lateral expansion of extrudates. A significant increase in water absorption index was (5.34 g/g to 6.23 $\mathrm{g} / \mathrm{g}$ ) observed at high moisture content. The negative regression coefficients of feed composition, barrel temperature and moisture content revealed that these parameters reduced water solubility index of extrudates. Higher moisture content depicted positive effect on breaking strength (178.71-325.77 N) whereas increased barley content significantly reduced effect on breaking strength. Lower values of bulk density were observed at lower values of moisture content. Low moisture content significantly reduced effect on bulk density. The specific mechanical energy of barley based extrudates ranged in between 221.07 to $327.45 \mathrm{~W} h r / k g$, a significant decrease in specific mechanical energy was observed at low moisture content. Feed composition, high moisture content and high barrel temperature enhanced the luminosity, redness and yellowness of extrudates. The extruded samples were evaluated organoleptically for appearance, texture, flavour and overall acceptability by semi trained panel of 10 judges using 5-point scales.
\end{abstract}

\section{Keywords: Barley; Extrusion process; Lentil; Pumpkin; RSM}

\section{Introduction}

Snack foods have become an important part of the diets of many individuals including children. Cereal grains are generally used as major raw material in extruded snack foods. Nutritious snack foods can be produced by incorporation of legumes, vegetables and fruits into the formulation. Studies have shown that consumption of grains, fruits and vegetables may reduce risk of chronic diseases and/or promote general human health. Barley is the world's fourth most important cereal crop, after wheat, maize (corn), and rice. Barley is the most prominent crop in feeding livestock as well as it is a main ingredient in beer or other malted beverages. Barley is high in carbohydrates, with moderate amounts of protein, calcium and phosphorus. It also has small amounts of the B vitamins. Scientific evidence indicates that including barley in a healthy diet can help reduce the risk of coronary heart diseases by lowering LDL and total cholesterol levels. It has superior nutritional qualities due to presence of beta-glucan (an anticholesterol substance), acetylcholine (a substance which nourishes our nervous system and recovers memory loss), easy digestibility (due to low gluten contents) and high lysine, thiamine and riboflavin. Barley food product provides cooling and soothering effect in body sustained for a longer time. Its alternate uses in malt and beer industry and health tonics have proved that barley is an important crop of the present era [1].

Lentil is one of the early domesticated plant species, as old as those of corn, wheat, barley and pea. Because of its high average protein content and fast cooking characteristics lentil is the most desired legume in many regions. Lentil seeds contain $1 \%$ to $2 \%$ fat, $24 \%$ to $32 \%$ proteins and minerals (iron, cobalt and iodine) and vitamins (lysine and arginine). Pumpkins are rich in carotene, vitamins, minerals and dietary fiber. $\beta$-carotene present in pumpkin is converted to vitamin $\mathrm{A}$ in the body and plays a crucial role in the prevention of chronic diseases during adult life due to their antioxidant abilities [2].

\section{Materials and Methods}

The present investigation was carried out in the Department of
Food Technology at Islamic University of Science and Technology. This section enlists the raw materials used and elaborates the processing techniques, analytical procedures, organoleptic evaluation and statistical methods followed during the research.

\section{Experimental raw material}

Raw materials used in the investigation: The barley was procured from local market in Kargil. The lentil was procured locally. The lentil was grinded into fine powder in FPTC lab in grinder. The pumpkin was procured locally. It was dried in hot air drier in FPTC lab at $70^{\circ} \mathrm{C}$ and grinded in grinder into fine flour. All the three flours were sieved through $200 \mu \mathrm{m}$ sieve.

\section{Physico-chemical characteristics of blended flours}

Moisture content (\%), Ash content (\%), crude protein, crude fibre and fat

Standard AACC procedures [3] were followed for the determination of moisture content, ash content, crude protein, crude fibre and fat.

Bulk density (g/cc): Bulk density was determined using the mass/ volume relationship by filling a cylindrical container of $500 \mathrm{ml}$ volume and tare weight with the grain by pouring from a constant height, striking off the top level and weighing.

*Corresponding author: Aabida Jabeen, Division of Food Technology, Islamic University of Science and Technology, Awantipora, India, Tel: 01933-247955 E-mail: abidaali2006@gmail.com

Received December 18, 2017; Accepted January 05, 2018; Published January 12,2018

Citation: Jabeen A, Hassan S, Masoodi L, Ajaz N, Rafiq A (2018) PhysicoChemical Composition and Functional Properties of Blended Flour Obtained from Lentil, Pumpkin and Barley for Development of Extrudates. J Food Process Technol 9: 713. doi: 10.4172/2157-7110.1000713

Copyright: () 2018 Jabeen A, et al. This is an open-access article distributed unde the terms of the Creative Commons Attribution License, which permits unrestricted use, distribution, and reproduction in any medium, provided the original author and source are credited. 
Citation: Jabeen A, Hassan S, Masoodi L, Ajaz N, Rafiq A (2018) Physico-Chemical Composition and Functional Properties of Blended Flour Obtained from Lentil, Pumpkin and Barley for Development of Extrudates. J Food Process Technol 9: 713. doi: 10.4172/2157-7110.1000713

\section{Rheological/pasting properties}

Pasting properties of flours and their blends were determined, using rapid visco-analyzer (RVA Starch Master TM, Newport Scientific, Warriewood, Australia). Flour sample (3.45 g, 12\% mb) was taken in RVA aluminium canister and $25 \mathrm{ml}$ of distilled water was added to it. It was then subjected to a programmed heating and cooling cycle where samples were held at $50^{\circ} \mathrm{C}$ for $1 \mathrm{~min}$, heated to $95^{\circ} \mathrm{C}$ for $7.5 \mathrm{~min}$ and held at $95^{\circ} \mathrm{C}$ for $2 \mathrm{~min}$. It was then cooled to $50^{\circ} \mathrm{C}$ in $7 \mathrm{~min}$ and then held at $50^{\circ} \mathrm{C}$ for $2 \mathrm{~min}$. The centrifuge rotating speed was maintained at $160 \mathrm{rpm}$. Parameters including pasting temperature, peak viscosity, breakdown, trough, setback, and final viscosity were recorded. Tests were performed in triplicates.

\section{Preparation of sample}

Blend of barley, lentil and pumpkin was made, in which pumpkin content was kept constant (7.5\%) in all the five treatments. Barley content varied from $50 \%$ to $90 \%$ and lentil content varied from $1.2 \%$ to $42.5 \%$. All the ingredients were weighed separately according to treatments and then mixed in Food Processor (make: Inalsa, $600 \mathrm{~W}$ ) with mixer attachment for a period of $20 \mathrm{~min}$. The mixtures were passed through a $200 \mathrm{~mm}$ sieve to reduce the lumps formed. After mixing, samples were stored in PET bottles at room temperature for 48 hours. The moisture content of all the samples was estimated using the hot air oven method [3].

\section{Extrusion process}

The extrusion experiment was performed in a BTPL lab model twin screw extruder [NMFP- MOFPI (GOI), SIDCO (J\&K], Division Post Harvest Technology, SKUAST-Kashmir, Shalimar Campus, Srinagar. The barrel diameter and its length to breadth ratio $(1 / \mathrm{b})$ were $2.5 \mathrm{~mm}$ and 16:1 respectively. The extruder barrel is divided into four zones. Temperature of first, second and third zone was maintained at $30^{\circ} \mathrm{C}$, $60^{\circ} \mathrm{C}$ and $90^{\circ} \mathrm{C}$ respectively, throughout the experiment, while the temperature at the fourth zone was varied to the experimental design. The extruder was equipped with a torque indicator, which showed per cent of torque in proportion to be current drawn by the drive motor.

\section{Physico-chemical characteristics of extruded products}

Specific Mechanical Energy (SME): Specific mechanical energy (Wh/kg) was calculated from rated screw speed (682) rpm), motor power rating, actual screw speed\% motor torque and mass flow rate $(\mathrm{kg} / \mathrm{h})$ as per the following formula [4].

Bulk density (g/cc): Bulk densities of extrudates were determined by volumetric displacement procedures as described by Patil et al. [5]. The volume of expanded sample was measured by using a 250 $\mathrm{ml}$ graduated cylinder by rapeseed displacement. The volume of $20 \mathrm{~g}$ randomised sample was measured for each test. The ratio of sample weight and the replaced volume in the cylinder was calculated as density (w/v).

Water Solubility Index (WSI) and Water Absorption Index (WAI): WSI and WAI were determined according to the method developed for cereals. The ground extrudate was suspended in water at room temperature for $30 \mathrm{~min}$, gently stirred during this period, and then centrifuged at $3000 \mathrm{~g}$ for $15 \mathrm{~min}$. The supernatant was decanted into an evaporating dish of known weight. WAI was the weight of gel obtained after removal of the supernatant per unit weight of original dry solids. WSI was the weight of dry solids in the supernatant expressed as a percentage of the original weight of sample.

Lateral expansion: The ratio of diameter of extrudate to the diameter of die was used to express the expansion of extrudate [6,7]. Six lengths of extrudate (approx. $60 \mathrm{~mm}$ ) was selected at random during the collection of each of the extruded samples and allowed to cool to room temperature. The diameter of the extrudates was then measured, at 5 different positions along the length of each of the ten samples, using a digital Vernier Calliper (Diginatic Solar Mitutoya, Japan).

Colour: Colour was determined by using Hunter Lab Colorimeter (Model SN 3001476, Accuracy Micro Sensors, New York). The instrument was calibrated with the user supplied black plate calibration standards that were used for zero setting. Minolta supplied white calibration setting was used for white calibration. The samples were uniformly packed in clean Petri plates with lids. The instrument was placed on the plate and their exposure at different places was conducted. Readings were displayed as $L^{*}, a^{*}, b^{*}$ colour parameter according to the CIELAB system of colour measurement. $\mathrm{L}^{*}$ (Luminosity or brilliance) varies from black (zero) to white $(100)$, a from green $(+100)$ to red $(-100)$ and $b^{*}$ from blue $(-100)$ to yellow $(+100)$.

Breaking strength: The hardness of the extrudates was checked by using texture analyzer (Model TA-TX, Stable Micro systems ltd, UK) equipped with $500 \mathrm{~kg}$ load cell and texture expert system for data collection. An extrudate $40 \mathrm{~mm}$ long was compressed with a probe SMS-P/75-75 $\mathrm{mm}$ diameter at a crosshead speed $5 \mathrm{~mm} / \mathrm{s}$ to $3 \mathrm{~mm}$ of $90 \%$ of diameter of the extrudate. The compression generated a curve with force over distance. The highest first peak value was recorded as this value indicated the first rupture of snack at one point and this value of force was taken as a measurement for hardness [8].

Sensory quality: Extruded snacks after mixing spices were evaluated for sensory attributes (colour, flavour, texture and overall acceptability) by a panel of $10 \mathrm{semi}$ trained judges using 5-point scale. The proforma used for sensory evaluation by ten semi-trained panellists for colour, texture, flavour and overall acceptability is given in Appendix-1.

Optimization: Numerical optimization of the process variables was performed with the help of Design Expert version 9.0.

\section{Experimental design}

Response Surface Methodology (RSM) was adopted in the experimental design as it emphasizes the modelling and analysis of the problem in which response of interest is influenced by several variables, and the objective is to optimize this response [9]. The main advantage of RSM is to reduce number of experimental runs needed to provide sufficient information for statistically acceptable results. A five level, three factor central composite rotatable design was employed. The independent variables selected for experiment were: Feed proportion (Barley Flour: Lentil flour: Pumpkin flour) (A), 50:42.5:7.5, 60:32.5:7.5, 70:22.5:7.5, 80:12.5:7.5 and 90:2.5:7.5; Moisture content (B), 13, 15, 17, 19 and $21 \%$ and barrel temperature (C), $115,125,135,145$ and $155^{\circ} \mathrm{C}$. The actual value of each level is detailed in the Tables 1-3.

\section{Results and Discussion}

The present investigation entitled "Studies on lentil and pumpkin incorporated barley extrudates" was carried out in the department of Food Technology at Islamic university of science and technology awantipora. The results obtained during investigation are given in Tables 4 and 5 .

\section{Proximate analysis of raw materials}

Physico-chemical characteristics of flour blends: The data in Table 4 revealed the proximate composition of blended flour. 
Citation: Jabeen A, Hassan S, Masoodi L, Ajaz N, Rafiq A (2018) Physico-Chemical Composition and Functional Properties of Blended Flour Obtained from Lentil, Pumpkin and Barley for Development of Extrudates. J Food Process Technol 9: 713. doi: 10.4172/2157-7110.1000713

Page 3 of 9

\begin{tabular}{|c|c|c|c|c|c|c|}
\hline \multirow{2}{*}{ Independent variables } & \multirow{2}{*}{ Code } & \multicolumn{5}{|c|}{ Levels in coded from } \\
\hline & & -1.68 & -1 & 0 & +1 & +1.68 \\
\hline Feed composition (ratio) & $A$ & $50: 42.5: 7.5$ & $60: 32.5: 7.5$ & $70: 22.5: 7.5$ & $80: 12.5: 7.5$ & $90: 2.5: 7.5$ \\
\hline Feed moisture (\%) & B & 13 & 15 & 17 & 19 & 21 \\
\hline Barrel temperature $\left({ }^{\circ} \mathrm{C}\right)$ & $\mathrm{C}$ & 115 & 125 & 135 & 145 & 155 \\
\hline
\end{tabular}

Table 1: Values of independent variables at five levels of the CCRD design.

\begin{tabular}{|c|c|c|c|}
\hline S. No. & Composition (B: L: P) & Moisture content (\%) & Barrel temperature $\left({ }^{\circ} \mathrm{C}\right)$ \\
\hline 1. & $60: 32.5: 7.5(-1)$ & $15.00(-1)$ & $125(-1)$ \\
\hline 2. & $80: 12.5: 7.5(+1)$ & $15.00(-1)$ & $125(-1)$ \\
\hline 3. & $60: 32.5 ; 7.5(-1)$ & $19.00(+1)$ & $125(-1)$ \\
\hline 4. & $80: 12.5: 7.5(+1)$ & $19.00(+1)$ & $125(-1)$ \\
\hline 5. & $60: 32.5: 7.5(-1)$ & $15.00(-1)$ & $145(+1)$ \\
\hline 6. & $80: 12.5: 7.5(+1)$ & $15.00(-1)$ & $145(+1)$ \\
\hline 7. & $60: 32.5: 7.5(-1)$ & $19.00(+1)$ & $145(+1)$ \\
\hline 8. & $80: 12.5: 7.5(+1)$ & $19.00(+1)$ & $145(+1)$ \\
\hline 9. & $50: 42.5: 7.5(-1.68)$ & $17.00(0)$ & $135(0)$ \\
\hline 10. & $90: 2.5: 7.5(+1.68)$ & $17.00(0)$ & $135(0)$ \\
\hline 11. & $70: 22.5: 7.5(0)$ & $13.00(-1.68)$ & $135(0)$ \\
\hline 12. & $70: 22.5: 7.5(0)$ & $21.00(+1.68)$ & $135(0)$ \\
\hline 13. & $70: 22.5: 7.5(0)$ & $17.00(0)$ & $115(-1.68)$ \\
\hline 14. & $70: 22.5: 7.5(0)$ & $17.00(0)$ & $155(+1.68)$ \\
\hline 15. & $70: 22.5: 7.5(0)$ & $17.00(0)$ & $135(0)$ \\
\hline 16. & $70: 22.5: 7.5(0)$ & $17.00(0)$ & $135(0)$ \\
\hline 17. & $70: 22.5: 7.5(0)$ & $17.00(0)$ & $135(0)$ \\
\hline 18. & $70: 22.5: 7.5(0)$ & $17.00(0)$ & $135(0)$ \\
\hline 19. & $70: 22.5: 7.5(0)$ & $17.00(0)$ & $135(0)$ \\
\hline 20. & $70: 22.5: 7.5(0)$ & $17.00(0)+$ & $135(0)$ \\
\hline
\end{tabular}

Table 2: Central composite rotatable experimental design (in coded and uncoded levels of three variables and five levels) employed for development of barley, lentil and pumpkin based extrudates.

\begin{tabular}{|c|c|c|c|c|c|}
\hline \multicolumn{3}{|c|}{ Coded variables } & \multirow{2}{*}{ Combinations } & \multirow{2}{*}{ Replications } \\
\hline \pm 1 & B & C & 8 & 1 \\
\hline \pm 1.68 & 0 & \pm 1 & 2 & 1 \\
\hline 0 & \pm 1.68 & 0 & 2 & 1 \\
\hline 0 & 0 & \pm 1.68 & 2 & 1 \\
\hline 0 & 0 & 0 & 6 & 0 \\
\hline
\end{tabular}

Code ' 0 ' is for centre point of the parameter range investigated, ' \pm 1 ' for factorial points, and ' \pm 1.68 ' for star points; ${ }_{\mathrm{A}}$-Feed Composition (\%), B Feed Moisture ( $\%$ ) and C.Barrel temperature $\left({ }^{\circ} \mathrm{C}\right)$

Table 3: Experimental design in coded form for response surface analysis.

\begin{tabular}{|c|c|c|c|c|}
\hline Components & Moisture (\%) & Ash (\%) & Fat (\%) & Protein (\%) \\
\hline Barley & 9.5 & 2.44 & 2.20 & 15.03 \\
\hline Lentil & 10 & 3.1 & 3.03 & 22.18 \\
\hline Pumpkin & 9.9 & 15.98 & 2.3 & 3.02 \\
\hline CD at P<0.05 & $\mathbf{0 . 2 6 9}$ & $\mathbf{2 0 1 . 0 9 4}$ & $\mathbf{0 . 7 0}$ & 3.07 \\
\hline
\end{tabular}

Table 4: Physico-chemical characteristics of individual flours.

\begin{tabular}{|c|c|c|c|c|c|c|}
\hline Treatment & Moisture (\%) & Ash (\%) & Fat (\%) & Protein (\%) & Fibre & Bulk density (g/cc) \\
\hline $\mathrm{T}_{1}(50 \mathrm{~B}: 42.5 \mathrm{~L}: 7.5 \mathrm{P})$ & 9.75 & 3.71 & 2.41 & 17.16 & 4.73 & 0.57 \\
\hline $\mathrm{T}_{2}(60 \mathrm{~B}: 32.5 \mathrm{~L}: 7.5 \mathrm{P})$ & 9.69 & 3.64 & 2.33 & 16.44 & 4.69 & 0.54 \\
\hline $\mathrm{T}_{3}(70 \mathrm{~B}: 22.5 \mathrm{~L}: 7.5 \mathrm{P})$ & 9.64 & 3.57 & 2.25 & 15.74 & 4.65 & 0.50 \\
\hline $\mathrm{T}_{4}(80 \mathrm{~B}: 12.5 \mathrm{~L}: 7.5 \mathrm{P})$ & 9.59 & 3.51 & 2.16 & 15.02 & 4.61 & 0.46 \\
\hline $\mathrm{T}_{5}(90 \mathrm{~B}: 2.5 \mathrm{~L}: 7.5 \mathrm{P})$ & 9.54 & 3.44 & 2.08 & 14.3 & 4.57 & 0.44 \\
\hline$C D$ at $P<0.05$ & NS & 0.33 & 0.41 & 3.36 & 0.19 & 0.15 \\
\hline
\end{tabular}

Table 5: Physico-chemical characteristics of blended flours. 
Citation: Jabeen A, Hassan S, Masoodi L, Ajaz N, Rafiq A (2018) Physico-Chemical Composition and Functional Properties of Blended Flour Obtained from Lentil, Pumpkin and Barley for Development of Extrudates. J Food Process Technol 9: 713. doi: 10.4172/2157-7110.1000713

Page 4 of 9

\begin{tabular}{|c|c|c|c|c|c|}
\hline Treatment & Pasting temperature $\left({ }^{\circ} \mathrm{C}\right)$ & Peak viscosity (cP) & Final viscosity (cP) & Breakdown viscosity (cP) & Setback viscosity (cP) \\
\hline $\mathrm{T}_{1}(50 \mathrm{~B}: 42.5 \mathrm{~L}: 7.5 \mathrm{P})$ & 73.45 & 1197 & 1852 & 139 & 794 \\
\hline $\mathrm{T}_{2}(60 \mathrm{~B}: 32.5 \mathrm{~L}: 7.5 \mathrm{P})$ & 75.05 & 1120 & 1797 & 47 & 724 \\
\hline $\mathrm{T}_{3}(70 \mathrm{~B}: 22.5 \mathrm{~L}: 7.5 \mathrm{P})$ & 75.05 & 1198 & 1964 & 66 & 832 \\
\hline $\mathrm{T}_{4}(80 \mathrm{~B}: 12.5 \mathrm{~L}: 7.5 \mathrm{P})$ & 86.40 & 1038 & 1859 & 84 & 905 \\
\hline $\mathrm{T}_{5}(90 \mathrm{~B}: 2.5 \mathrm{~L}: 7.5 \mathrm{P})$ & 85.50 & 1369 & 2350 & 106 & 1087 \\
\hline CD at $P<0.05$ & 18.629 & 385.90 & 223.05 & 112.56 & 436.50 \\
\hline
\end{tabular}

Table 6: Pasting/Rheological properties of blended flours.

\begin{tabular}{|c|c|c|c|c|c|c|}
\hline Regression & SME (Wh/kg) & Bulk density (g/cc) & WAI $(g / g)$ & WSI (\%) & Expansion Index & Break strength $(\mathrm{N})$ \\
\hline Adequate precision & 22.717 & 8.802 & 9.952 & 26.025 & 24.611 & 9.079 \\
\hline R square & 0.9709 & 0.8490 & 0.9055 & 0.9815 & 0.9796 & 0.8080 \\
\hline Adjusted R square & 0.9447 & 0.7131 & 0.8204 & 0.9649 & 0.9612 & 0.6351 \\
\hline Predicted R square & 0.8787 & 0.4733 & 0.7078 & 0.9141 & 0.8808 & 0.3409 \\
\hline C.V. (\%) & 2.76 & 17.82 & 1.94 & 5.04 & 3.84 & 7.69 \\
\hline Lack of fit ( $p$ value) & 0.6497 & 0.7711 & 0.8675 & 0.4986 & 0.2484 & 0.8610 \\
\hline
\end{tabular}

Table 7: Analysis of variance for the Fit of experimental data to response surface models.

\begin{tabular}{|c|c|c|c|c|c|c|c|c|}
\hline FC (\%) B: L: P & MC (\%) & BT $\left({ }^{\circ} \mathrm{C}\right)$ & SME (Whr/kg) & $\mathrm{BD}(\mathrm{g} / \mathrm{cc})$ & EI & WAI (g/g) & WSI (\%) & Hardness (N) \\
\hline$(-1)$ & $(-1)$ & $(-1)$ & 304.72 & 0.08 & 42.4 & 5.34 & 0.255 & 240.49 \\
\hline$(+1)$ & $(-1)$ & $(-1)$ & 281.71 & 0.039 & 70.8 & 5.55 & 0.15 & 181.41 \\
\hline$(-1)$ & $(+1)$ & $(-1)$ & 227.25 & 0.15 & 37 & 5.89 & 0.15 & 301.18 \\
\hline$(+1)$ & $(+1)$ & $(-1)$ & 249.78 & 0.18 & 54.6 & 5.85 & 0.125 & 261.66 \\
\hline$(-1)$ & $(-1)$ & $(+1)$ & 327.45 & 0.09 & 68 & 5.7 & 0.22 & 217.49 \\
\hline$(+1)$ & $(-1)$ & $(+1)$ & 271.39 & 0.083 & 69.8 & 6.06 & 0.15 & 261.45 \\
\hline$(-1)$ & $(+1)$ & $(+1)$ & 221.07 & 0.098 & 49 & 5.66 & 0.13 & 275.89 \\
\hline$(+1)$ & $(+1)$ & $(+1)$ & 234.22 & 0.18 & 49.54 & 5.54 & 0.12 & 256.87 \\
\hline$(-1.68)$ & $(0)$ & $(0)$ & 290.56 & 0.125 & 46 & 5.61 & 0.23 & 264.34 \\
\hline$(+1.68)$ & (0) & (0) & 257.29 & 0.142 & 68.4 & 5.95 & 0.15 & 226.43 \\
\hline (0) & $(-1.68)$ & (0) & 326.75 & 0.07 & 72 & 5.85 & 0.21 & 214.68 \\
\hline$(0)$ & $(+1.68)$ & $(0)$ & 208.46 & 0.161 & 39.32 & 6.16 & 0.1 & 289.99 \\
\hline$(0)$ & (0) & $(-1.68)$ & 255.55 & 0.13 & 45 & 5.45 & 0.125 & 245.15 \\
\hline (0) & (0) & $(+1.68)$ & 262.93 & 0.074 & 62.2 & 5.47 & 0.12 & 262.13 \\
\hline (0) & (0) & (0) & 284.12 & 0.142 & 64.6 & 6.23 & 0.135 & 212.57 \\
\hline (0) & (0) & (0) & 266.15 & 0.166 & 61.31 & 5.98 & 0.15 & 211.34 \\
\hline (0) & (0) & (0) & 274.73 & 0.11 & 63.21 & 5.95 & 0.135 & 247.92 \\
\hline (0) & (0) & (0) & 284.12 & 0.142 & 64.6 & 6.23 & 0.135 & 212.57 \\
\hline (0) & (0) & (0) & 266.15 & 0.166 & 60.02 & 5.98 & 0.15 & 211.34 \\
\hline (0) & (0) & (0) & 274.73 & 0.11 & 63.23 & 5.95 & 0.135 & 262.13 \\
\hline
\end{tabular}

FC (\%): Feed Composition (B: Barley; L: Lentil; P: Pumpkin); MC (\%): Moisture Content; BT ( $\left.{ }^{\circ} \mathrm{C}\right)$ : Barrel Temperature; SME (wh/Kg): Specific Mechanical Energy; BD (g/ cc): Bulk Density; WAI (g/g): Water Absorption Index; WSI (\%): Water Solubility Index; El: Expansion Index; N: Hardness

Table 8: Effect of processing conditions on product characteristics of lentil and pumpkin incorporated barley based extrudates.

\section{Pasting/rheological properties of blended flours}

Significant differences $(\mathrm{p}<0.05)$ were observed among pasting properties of flour samples of blend of barley, lentil and pumpkin as presented in Table 6. Pasting temperature $\left(73.45^{\circ} \mathrm{C}\right.$ to $\left.86.40^{\circ} \mathrm{C}\right)$, Peak viscosity (1038-1369 C $\mathrm{C}_{\mathrm{p}}$ ). Blended flours recorded peak viscosity, breakdown viscosity and final viscosity, set back viscosity as given in Table 6.

\section{Extrusion processing}

Experimental design: Response Surface Methodology (RSM) software dxt trail 9.01 version was used to investigate the effects of processing conditions on product characteristics. The independent variables included the feed composition ( $50 \%$ to $90 \%$ barley flour; $2.5 \%$ to $42.5 \%$ lentil flour; $7.5 \%$ pumpkin flour), moisture content (13\% to $21 \%)$, and barrel temperature $\left(115^{\circ} \mathrm{C}\right.$ to $\left.155^{\circ} \mathrm{C}\right)$. Response variables were-specific mechanical energy (SME), bulk density (BD), water absorption index (WAI), water solubility index (WSI), expansion index (EI), texture (Hardness) and instrumental colour $\left(\mathrm{L}^{*}, \mathrm{a}^{*}, \mathrm{~b}^{*}\right.$, hue angle and chrome).

Effect of independent variables on product characteristics of lentil and pumpkin incorporated barley based extrudates: Models for all parameters were significant and all parameters were significantly affected by lentil and pumpkin incorporation, moisture and barrel temperature. None of the models showed significant lack of fit, indicating that all second order polynomial models correlated well with the measured data. Adequate precision (signal to noise ratio) greater than 4 is desirable (Table 7). All the parameters showed high adequate precision. A reasonable good coefficient of determination $\left(\mathrm{R}^{2}=0.97,0.84,0.97,0.90,0.98,0.84\right.$ for SME, bulk density, expansion index, WAI, WSI and texture (hardness) respectively) indicated that models developed for product response appeared to be adequate. The predicted R-square was found in reasonable agreement with adjusted $\mathrm{R}$-square for all the parameters. 
Citation: Jabeen A, Hassan S, Masoodi L, Ajaz N, Rafiq A (2018) Physico-Chemical Composition and Functional Properties of Blended Flour Obtained from Lentil, Pumpkin and Barley for Development of Extrudates. J Food Process Technol 9: 713. doi: 10.4172/2157-7110.1000713

Page 5 of 9

\section{System extruder property}

Specific Mechanical Energy (SME): The mean values of SME under different extrusion conditions listed in Table 8 ranged between 221.07 to $327.45 \mathrm{whr} / \mathrm{kg}$ with an average value of $268.456 \mathrm{whr} / \mathrm{kg}$. Regression analysis and response surface plots (Figure 1) showed the negative effect of feed composition and moisture and positive effect of barrel temperature. During extrusion higher the SME, higher is the degree of gelatinization. Since mechanical energy favours gelatinization by promoting rupture of intermolecular hydrogen bonds [10].

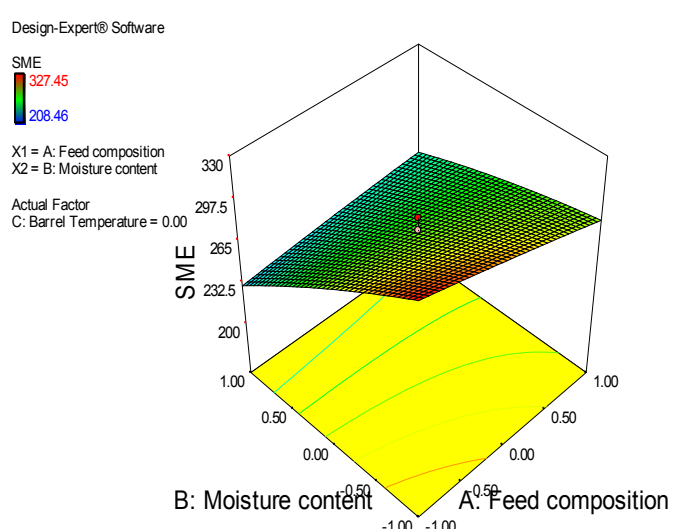

Figure 1: Effect of feed composition and moisture on SME of lentil and pumpkin incorporated barley extrudates.

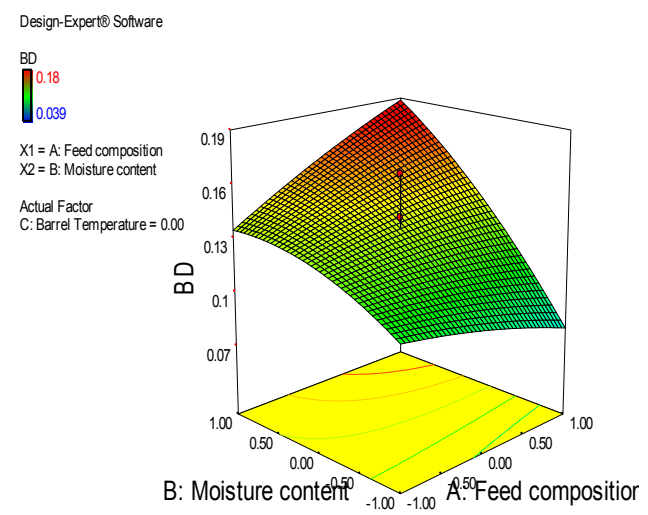

Figure 2: Effect of feed composition and moisture content on BD of lentil and pumpkin incorporated barley extrudates.

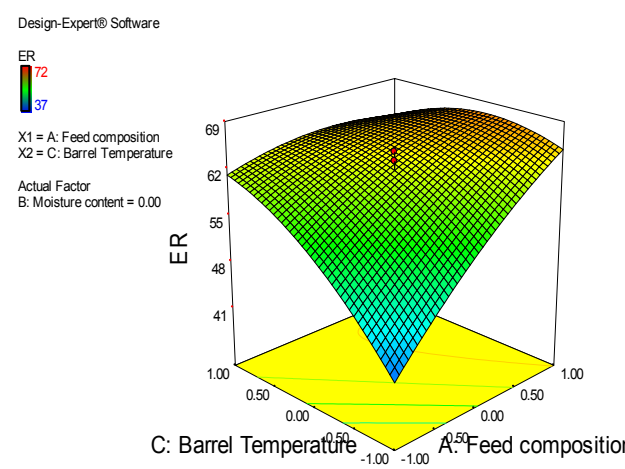

Figure 3: Effect of feed composition and barrel temperature on lateral expansion of lentil and pumpkin incorporated barley extrudates.

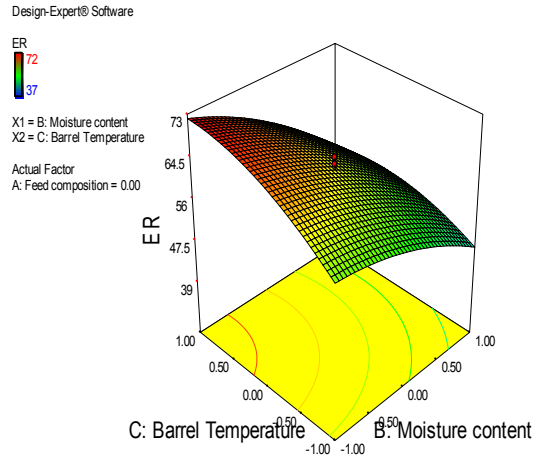

Figure 4: Effect of moisture content and barrel temperature on lateral expansion of lentil and pumpkin incorporated barley extrudates.

\section{Physical properties of extruded snacks}

Bulk density: The maximum bulk density $(0.18 \mathrm{~g} / \mathrm{cc})$ of extrudates was about 4.6 times more than the minimum bulk density $(0.039 \mathrm{~g} /$ $\mathrm{cc}$ ) and the average value of bulk density was $0.121 \mathrm{~g} / \mathrm{cc}$. It showed the positive relation of feed composition and moisture content and inverse relation of temperature with bulk density. Similar reports were observed by Shivani et al. [11] that increased feed moisture content during extrusion may reduce the elasticity of the dough through plasticization of the melt, therefore reduced gelatinization and increasing the density of extrudate (Figure 2).

Lateral expansion: The mean value of expansion index under different extrusion conditions listed in Table 8 ranged from 37 to 70.8 . Regression analysis and response surface plots (Figures 3-6) showed the positive effect of composition and temperature, while the negative effect of moisture on expansion index. Similar reports were observed by Omohimi et al. [12], that there was an appreciable increase in lateral expansion as barrel temperature increases. High input of thermal energy due to high residence time leads to the creation of enhanced level of superheated steam; hence the product will have good expansion which creates flashy and porous structures due to formation of air cells. When extrusion cooked melt exits the die, they suddenly go from high pressure to atmospheric pressure. This pressure drop causes a flash-off of internal moisture and the water vapour pressure, which is nucleated to form bubbles in the molten extrudate, allows the expansion of the melt.

Water Absorption Index (WAI): Water absorption index of extrudates varied in the range of 5.34 to $6.23 \mathrm{~g} / \mathrm{g}$ with an average value of $5.82 \mathrm{~g} / \mathrm{g}$. Change in feed composition, increase in moisture content and increase in barrel temperature increased the water absorption index. Similar reports were observed by Shivani et al. [11] that water absorption index increased with the increase in temperature probably due to increased dextrinization at higher temperature [12].

Water Solubility Index (WSI): Water solubility index of extrudates ranged from $0.1 \%$ to $0.25 \%$ with an average value of $0.13 \%$. The analysis of variance and response surface plots (Figures 7 and 8) showed the negative influence of feed composition, moisture content and barrel temperature. Vilma et al. [13] reported that Water solubility index (WSI) is used as a measure for starch degradation; it means that at lower WSI there is minor degradation of starch and such condition leads to less numbers of soluble molecules in the extrudates. Higher moisture content in extrusion process can diminish protein denaturation and starch degradation. 
Citation: Jabeen A, Hassan S, Masoodi L, Ajaz N, Rafiq A (2018) Physico-Chemical Composition and Functional Properties of Blended Flour Obtained from Lentil, Pumpkin and Barley for Development of Extrudates. J Food Process Technol 9: 713. doi: 10.4172/2157-7110.1000713

Page 6 of 9

Breaking strength: The maximum breaking strength (325.77 $\mathrm{N})$ was about 1.82 times more than the minimum breaking strength $(178.71 \mathrm{~N})$ and the average value of breaking strength was $(242.89$ $\mathrm{N})$. The regression analysis and response surface plots (Figures 9-11) showed the negative effect of feed composition and moisture content and positive effect of barrel temperature.

Effect of processing conditions on colour coordinates and sensory attributes (overall acceptability) of lentil and pumpkin incorporated barley based extrudates

Models for all colour coordinates were significant and all coordinates were significantly affected by lentil and pumkin incorporation, feed moisture and barrel temperature. None of the models showed significant lack of fit, indicating that all second order

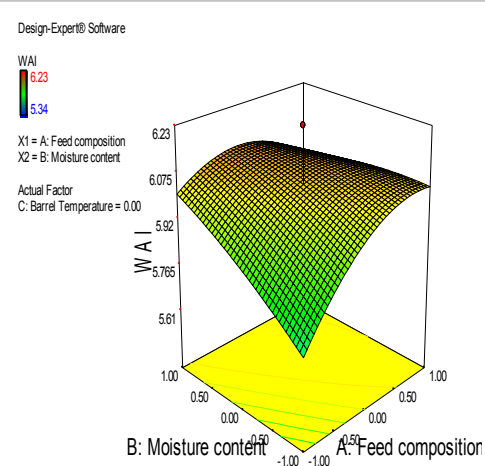

Figure 5: Effect of feed composition and moisture content on WAI of lentil and pumpkin incorporated barley based extrudates.

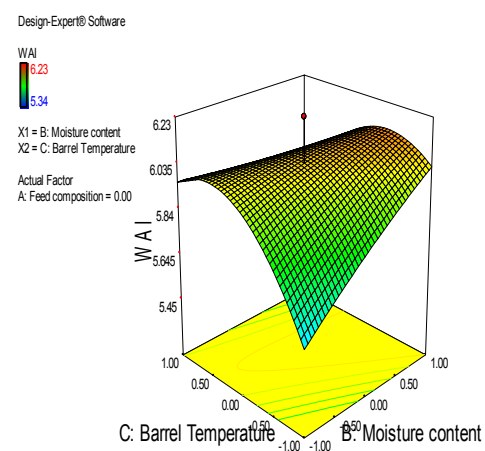

Figure 6: Effect of moisture content and barrel temperature on WAI of lentil and pumpkin incorporated barley based extrudates.

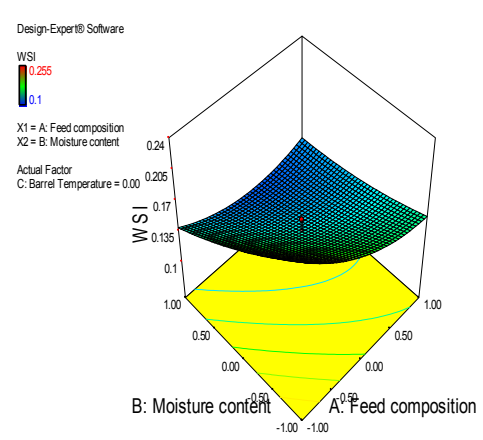

Figure 7: Effect of feed composition and moisture content on WSI of lentil and pumpkin incorporated barley based extrudates.

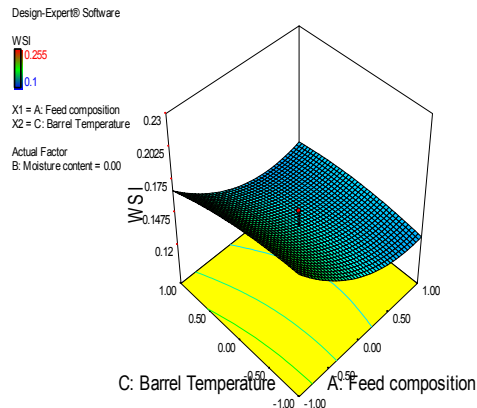

Figure 8: Effect of feed composition and barrel temperature on WSI of lentil and pumpkin incorporated barley based extrudates.

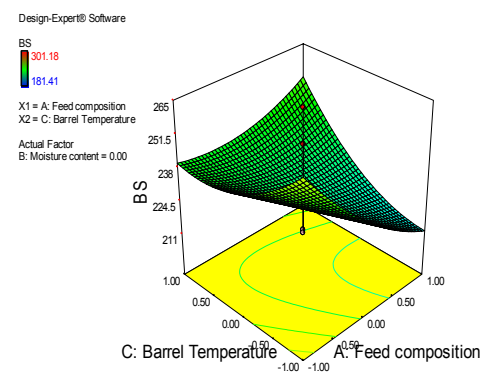

Figure 9: Effect of feed composition and barrel temperature on breaking strength of lentil and pumpkin incorporated barley extrudates.

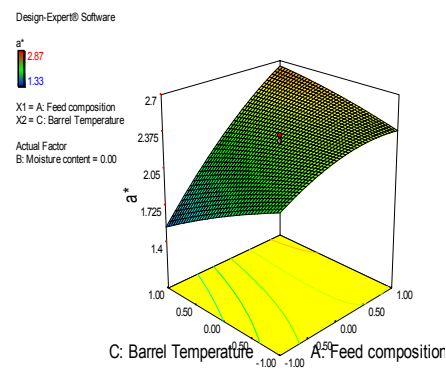

Figure 10: Effect of feed composition and barrel temperature on $\mathrm{a}^{*}$ of lentil and pumpkin incorporated barley extrudates.

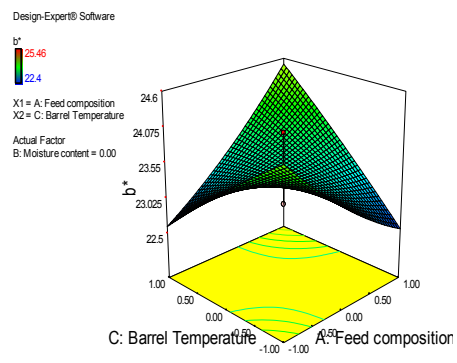

Figure 11: Effect of feed composition and barrel temperature on $b^{*}$ of lentil and pumpkin incorporated barley extrudates.

polynomial models correlated well with the measured data. Adequate precision (signal to noise ratio) greater than 4 is desirable (Table 9). All the parameters showed high adequate precision. A reasonable good coefficient of determination $\left(\mathrm{R}^{2}=0.34,0.99,0.85,0.99,0.85\right.$ for $\mathrm{L}^{*}, \mathrm{a}^{*}$, $\mathrm{b}^{*}$, hue angle and chrome value respectively) indicated that models developed for product response appeared to be adequate. The predicted 
Citation: Jabeen A, Hassan S, Masoodi L, Ajaz N, Rafiq A (2018) Physico-Chemical Composition and Functional Properties of Blended Flour Obtained from Lentil, Pumpkin and Barley for Development of Extrudates. J Food Process Technol 9: 713. doi: 10.4172/2157-7110.1000713

Page 7 of 9

\begin{tabular}{|c|c|c|c|c|c|}
\hline Regression & $\mathbf{L}^{*}$ & $\mathbf{a}^{*}$ & $\mathbf{b}^{*}$ & Hue angle $^{\mathbf{0}}$ & Chrome \\
\hline Adequate precision & 2.253 & 46.783 & 8.694 & 113.763 & 9.125 \\
\hline R square & 0.3445 & 0.9923 & 0.8596 & 0.9990 & 0.8577 \\
\hline Predicted R square & -0.7837 & 0.9560 & 0.3360 & 0.9942 & 0.3169 \\
\hline Adjusted R square & -0.2454 & 0.9853 & 0.7331 & 0.9981 & 0.7296 \\
\hline C.V. (\%) & 5.87 & 2.06 & 2.11 & 0.044 & 2.07 \\
\hline Lack of fit (p value) & 0.9247 & 0.2029 & 0.4554 & 0.2503 & 0.4359 \\
\hline
\end{tabular}

Table 9: Analysis of variance for the Fit of experimental data to response surface models.

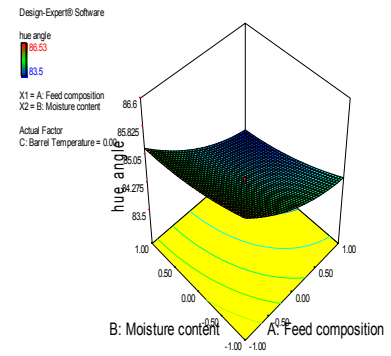

Figure 12: Effect of feed composition and moisture on hue angle of lentil and pumpkin incorporated barley based extrudates.

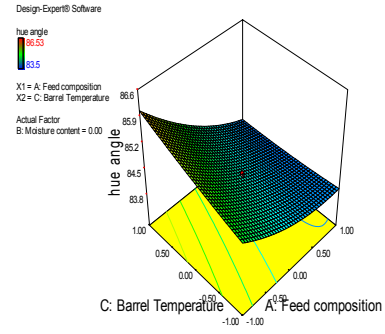

Figure 13: Effect of feed composition and barrel temperature on hue angle of lentil and pumpkin incorporated barley based extrudates.

\begin{tabular}{|c|c|c|c|c|c|c|c|}
\hline $\begin{array}{c}\mathbf{F C}(\%) \\
\text { B: } \mathbf{L}: \mathbf{P}\end{array}$ & $\mathbf{M C}(\%)$ & $\mathbf{B T}\left({ }^{\circ} \mathbf{C}\right)$ & $\mathbf{L}^{*}$ & $\mathbf{a}^{*}$ & $\mathbf{b}^{*}$ & $\mathbf{H A}$ & $\mathbf{C H}$ \\
\hline$(-1)$ & $(-1)$ & $(-1)$ & 44.82 & 1.99 & 25.11 & 85.46 & 25.18 \\
\hline$(+1)$ & $(-1)$ & $(-1)$ & 46.23 & 2.22 & 23.32 & 84.56 & 23.42 \\
\hline$(-1)$ & $(+1)$ & $(-1)$ & 45.41 & 2.34 & 25.31 & 84.71 & 25.41 \\
\hline$(+1)$ & $(+1)$ & $(-1)$ & 44.63 & 2.61 & 23.09 & 83.55 & 23.23 \\
\hline$(-1)$ & $(-1)$ & $(+1)$ & 42.2 & 1.33 & 22.4 & 86.60 & 22.43 \\
\hline$(+1)$ & $(-1)$ & $(+1)$ & 46.6 & 2.39 & 24.56 & 84.44 & 24.67 \\
\hline$(-1)$ & $(+1)$ & $(+1)$ & 46.4 & 1.72 & 24.25 & 85.94 & 24.31 \\
\hline$(+1)$ & $(+1)$ & $(+1)$ & 43.68 & 2.87 & 25.19 & 83.50 & 25.35 \\
\hline$(-1.68)$ & $(0)$ & $(0)$ & 43.09 & 1.44 & 23.28 & 86.46 & 23.32 \\
\hline$(+1.68)$ & $(0)$ & $(0)$ & 42.97 & 2.61 & 24.35 & 83.88 & 24.48 \\
\hline$(0)$ & $(-1.68)$ & $(0)$ & 43.38 & 2.06 & 25.39 & 85.36 & 25.47 \\
\hline$(0)$ & $(+1.68)$ & $(0)$ & 46.7 & 2.6 & 25.46 & 84.16 & 25.59 \\
\hline$(0)$ & $(0)$ & $(-1.68)$ & 42.66 & 2.33 & 22.81 & 84.16 & 22.92 \\
\hline$(0)$ & $(0)$ & $(+1.68)$ & 44.51 & 2.14 & 23.74 & 84.84 & 23.83 \\
\hline$(0)$ & $(0)$ & $(0)$ & 47.06 & 2.27 & 22.94 & 84.34 & 23.05 \\
\hline$(0)$ & $(0)$ & $(0)$ & 50.18 & 2.3 & 23.22 & 84.34 & 23.33 \\
\hline$(0)$ & $(0)$ & $(0)$ & 42.71 & 2.35 & 24 & 84.40 & 24.11 \\
\hline$(0)$ & $(0)$ & $(0)$ & 47.06 & 2.27 & 22.94 & 84.34 & 23.05 \\
\hline$(0)$ & $(0)$ & $(0)$ & 50.18 & 2.3 & 23.22 & 84.34 & 23.33 \\
\hline$(0)$ & $(0)$ & $(0)$ & 42.71 & 2.35 & 24 & 84.40 & 24.11 \\
\hline
\end{tabular}

FC (\%): Feed Composition (CF: Corn Flour; WCF: Water Chestnut Flour); MC (\%): Moisture Content; SS (rpm): Screw Speed; BT $\left({ }^{\circ} \mathrm{C}\right)$ : Barrel Temperature; OAA: Overall Acceptability

Table 10: Effect of processing conditions on colour coordinates of lentil and pumpkin incorporated barley based extrudates.

\begin{tabular}{|c|c|c|c|c|}
\hline S.no. & $\begin{array}{c}\text { A: Composition } \\
\text { (B:L:P) (\%) }\end{array}$ & B: Moisture (\%) & $\begin{array}{c}\text { C: Barrel tem- } \\
\left.\text { perature } \mathbf{~}^{\circ} \mathbf{C}\right)\end{array}$ & $\begin{array}{c}\text { Overall accept- } \\
\text { ability }\end{array}$ \\
\hline 1 & $60: 32.5: 7.5$ & 15 & 125 & 3.01 \\
\hline 2 & $80: 12.5: 7.5$ & 15 & 125 & 3.73 \\
\hline 3 & $60: 32.5: 7.5$ & 19 & 125 & 3.06 \\
\hline 4 & $80: 12.5: 7.5$ & 19 & 125 & 2.57 \\
\hline 5 & $60: 32.5: 7.5$ & 15 & 145 & 3.18 \\
\hline 6 & $80: 12.5: 7.5$ & 15 & 145 & 3.13 \\
\hline 7 & $60: 32.5: 7.5$ & 19 & 145 & 3.12 \\
\hline 8 & $8: 12.5: 7.5$ & 19 & 145 & 3.03 \\
\hline 9 & $50: 42.5: 7.5$ & 17 & 135 & 3.29 \\
\hline 10 & $90: 2.5: 7.5$ & 17 & 135 & 3.11 \\
\hline 11 & $70: 22.5: 7.5$ & 13 & 135 & 3.17 \\
\hline 12 & $70: 22.5: 7.5$ & 21 & 135 & 3.24 \\
\hline 13 & $70: 22.5: 7.5$ & 17 & 115 & 2.94 \\
\hline 14 & $70: 22.5: 7.5$ & 17 & 155 & 3.04 \\
\hline 15 & $70: 22.5: 7.5$ & 17 & 135 & 2.96 \\
\hline 16 & $70: 22.5: 7.5$ & 17 & 135 & 2.72 \\
\hline 17 & $70: 22.5: 7.5$ & 17 & 135 & 3.32 \\
\hline 18 & $70: 22.5: 7.5$ & 17 & 135 & 2.96 \\
\hline 19 & $70: 22.5: 7.5$ & 17 & 135 & 2.72 \\
\hline 20 & $70: 22.5: 7.5$ & 17 & 135 & 3.32 \\
\hline B: Barley; L: Lentil; P: Pumpkin & & & \\
\hline & -519 & & & \\
\hline
\end{tabular}

Table 11: Scores given by subjective method of evaluation.

R-square was found in reasonable agreement with adjusted R-square for all colour coordinates.

Colour- an important quality factor is directly related to the acceptability of food products. $\mathrm{L}^{*}$ indicates the brightness, $\mathrm{a}^{*}$-the redness and $\mathrm{b}^{*}$-the yellowness of extrudates. The mean values of $\mathrm{L}^{*}, \mathrm{a}^{*}$ and $\mathrm{b}^{*}$ of extrudates depicted in Table 9 was found in the range of 42.2 to 50.18, 1.33 to 2.87 and 22.4 to 25.46 respectively. The colour change during the extrusion process can also be an indicator to evaluate the intensity of the process in terms of chemical and nutritional changes [14]. The most prominent effect on the lightness of extrudates is of temperature which may be due to the non-enzymatic browning (Maillard reaction and Caramelization). Colour of extruded products is influenced by temperature, raw material composition, residence time; pressure and shear force [15].

$\mathbf{L}^{*}, \mathbf{a}^{*}$, and $\mathbf{b}^{*}$-values: Change of feed composition increase in moisture content and increase in barrel temperature increases $\mathrm{L}^{*}$ value. With the change in feed composition and increase in moisture content, $a^{*}$ value increases, whereas increase in barrel temperature will decrease $a^{*}$ value. Change in feed composition, increase in moisture content and extrusion temperature will increase the $b^{*}$ value of blended extrudate i.e., the intensity of yellowness of the extrudates increases.

Hue angle and chrome value: The analysis of variance (ANOVA) and response surface plots (Figures 12 and 13) showed that hue angle increased with increase barrel temperature and decreased with change in feed composition and increase in moisture content. With the change in feed composition, increase moisture content and increase in extrusion temperature the chrome value also increased.

\section{Sensory evaluation (overall acceptability)}

The extruded samples were evaluated organoleptically for appearance, texture, flavour and overall acceptability by semi trained panel of 10 judges using 5 point scale. Out of 20 samples only 6 samples at serial numbers $4,13,15,16,18$ and 19 were found fair with less than three overall acceptability score (Table 10 ). 
Citation: Jabeen A, Hassan S, Masoodi L, Ajaz N, Rafiq A (2018) Physico-Chemical Composition and Functional Properties of Blended Flour Obtained from Lentil, Pumpkin and Barley for Development of Extrudates. J Food Process Technol 9: 713. doi: 10.4172/2157-7110.1000713

Page 8 of 9

\section{Optimization}

Optimization can be defined as the processing conditions that give the optimum value of a function of certain decided variables subjected to constraints that are imposed. Optimization may be the process maximizing a desired quality or minimizing an undesired one. The values of the processing variables that produce the desired optimum value are called optimum conditions. Product responses such as SME, bulk density, WAI, WSI, expansion index and hardness are major parameters that determine the quality of extruded products (Table 11). Therefore, optimum conditions for the development of lentil and pumpkin incorporated barley blended snacks were determined to obtain the minimum bulk density, hardness and maximum SME, WAI, WSI and expansion ratio. The desirability function for obtaining optimal conditions in extrusion cooking of lentil and pumpkin incorporated barley blended flours of the response surface is shown in (Figures 14 and 15). The desirability obtained was 0.975 . The optimum lentil and pumpkin incorporation, moisture and barrel temperature were $12.5 \%, 7.5 \%, 15 \%$ and $125^{\circ} \mathrm{C}$ respectively (Tables 12 and 13 ).

\section{Summary and Conclusion}

Cereal grains are generally used as major raw material in extruded snack foods. Barley is high in carbohydrates, with moderate amounts of protein, calcium and phosphorus. In order to enhance the nutritional value of barley based extrudates, an attempt has been made to incorporate lentil and pumpkin in extrudates. Lentil is a rich source of lysine whereas pumpkin being a good source of fibre. Twin screw extruder was used for production of extrudates at varying

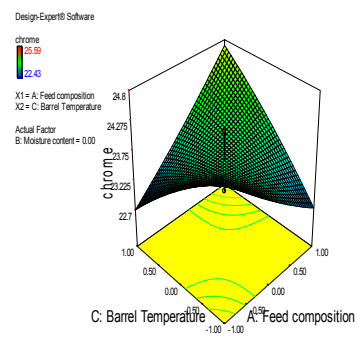

Figure 14: Effect of feed composition and barrel temperature on chrome of lenti and pumpkin incorporated barley based extrudate.

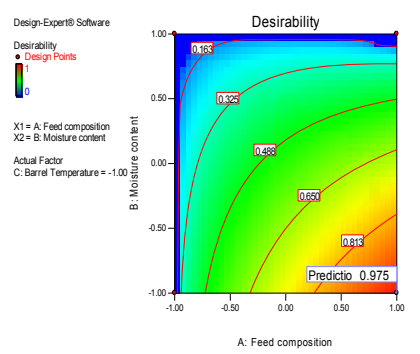

Figure 15: Desirability function response surface for lentil and pumpkin incorporated barley blended extrudates.

\begin{tabular}{|c|c|c|c|c|c|c|}
\hline Values & $\underset{\mathbf{k g}}{\text { SME Wh/ }}$ & $\begin{array}{c}\text { Bulk } \\
\text { density } \\
\left(\mathrm{kg} / \mathrm{m}^{3}\right)\end{array}$ & WAI $(g / g)$ & WSI (\%) & $\begin{array}{l}\text { Lateral } \\
\text { Expan- } \\
\text { sion (\%) }\end{array}$ & $\begin{array}{l}\text { Breaking } \\
\text { strength } \\
\text { (N) }\end{array}$ \\
\hline $\begin{array}{l}\text { Predicted } \\
\text { values }\end{array}$ & 277.67 & 0.041 & 5.60 & 0.15 & 70.21 & 187.96 \\
\hline Actual values & 281.71 & 0.040 & 5.55 & 0.15 & 70.80 & 181.41 \\
\hline Variation (\%) & 3.48 & 2.43 & 0.89 & 0 & 0.83 & 3.48 \\
\hline
\end{tabular}

Table 12: Predicted response levels and actual response levels.

\begin{tabular}{|c|c|}
\hline Parameters & Mean \pm SD \\
\hline Moisture (\%) & $5.5 \pm 0.288$ \\
\hline Protein (\%) & $8.69 \pm 0.034$ \\
\hline Fat (\%) & $1.32 \pm 0.011$ \\
\hline Ash (\%) & $2.03 \pm 0.017$ \\
\hline Fibre (\%) & $2.65 \pm 0.028$ \\
\hline $\mathrm{L}^{*}$ & $46.23 \pm 0.017$ \\
\hline $\mathrm{a}^{*}$ & $2.22 \pm 0.017$ \\
\hline $\mathrm{b}^{*}$ & $23.32 \pm 0.017$ \\
\hline Hue & $84.56 \pm 0.034$ \\
\hline Chrome & $23.42 \pm 0.011$ \\
\hline Breaking strength (N) & $181.41 \pm 0.23$ \\
\hline
\end{tabular}

Table 13: Proximate composition of final extruded snacks.

conditions (feed composition (50\% to $90 \%$ barley flour; $2.5 \%$ to $42.5 \%$ lentil flour and $7.5 \%$ pumpkin flour), moisture content $13 \%$ to $21 \%$ and barrel temperature $115^{\circ} \mathrm{C}$ to $155^{\circ} \mathrm{C}$ ). Higher moisture content was found to enhance the water absorption index of extrudates. Lower moisture content had negative effect on bulk density. Lateral expansion of extrudates were found to decrease with increase in barrel temperature and barley content. An inverse effect of feed composition, barrel temperature and moisture content on water solubility index of extrudates were observed. The color characteristics of barley based extrudates enhanced at higher extrusion conditions. The extruded samples were evaluated organoleptically for appearance, texture, flavour and overall acceptability, the optimised results were found at feed composition $80 \%$ barley flour, $12.5 \%$ lentil flour and $7.5 \%$ pumpkin flour; moisture content $15 \%$ and barrel temperature $125^{\circ} \mathrm{C}$. Low barrel temperature and low moisture content were found to enhance the lateral expansion (37-70.8) whereas low barley content significantly reduced lateral expansion of extrudates. A significant increase in water absorption index was ( $5.34 \mathrm{~g} / \mathrm{g}$ to $6.23 \mathrm{~g} / \mathrm{g}$ ) observed at high moisture content. The negative regression coefficients of feed composition, barrel temperature and moisture content revealed that these parameters reduced water solubility index of extrudates. Higher moisture content depicted positive effect on breaking strength (178.71 $\mathrm{N}-325.77 \mathrm{~N}$ ) whereas increased barley content significantly reduced effect on breaking strength. Lower values of bulk density were observed at lower values of moisture content. Low moisture content significantly reduced effect on bulk density. The specific mechanical energy of barley based extrudates ranged in between 221.07 to $327.45 \mathrm{~W} \mathrm{hr} / \mathrm{kg}$, a significant decrease in specific mechanical energy was observed at low moisture content. Feed composition, high moisture content and high barrel temperature enhanced the luminosity, redness, and yellowness of extrudates.

\section{References}

1. Sarfaraz KM, Mohyuddin H, Khalid UK, Muhammad AK, Muhammad S, et al (2012) Barley (Hordeum vulgare L.): A prophetic food mentioned in ahadith and its ethnobotanical importance. America J Agri Environ Sci 12: 835-841.

2. Usha R, Lakshmi M, Ranjani M (2010) Nutritional, sensory and physical analysis of pumpkin flour incorporated into weaning mix. Malaysia J Nutri 16: 379-387.

3. AACC (2000) Approved methods of American Association of Cereal Chemists. The Association St. Paul, MN, USA.

4. Pansawat N, Jangchud K, Jangchud A, Wuttjumnong P, Saalia FK, et al. (2008) Effects of extrusion conditions on secondary extrusion variables and physical properties of fish, rice-based snacks. Lebensmittel Wissenschaft Technol 41: 632-641.

5. Patil RT, Berrios JG, Swansons BG (2007) Evaluation of methods for expansion properties of legumes extrudates. Appl Eng Agri 23: 777-783.

6. Ainsworth P, Ibanoglu S, Ozer AE, Plunkett A (2006) Physical and sensory 
Citation: Jabeen A, Hassan S, Masoodi L, Ajaz N, Rafiq A (2018) Physico-Chemical Composition and Functional Properties of Blended Flour Obtained from Lentil, Pumpkin and Barley for Development of Extrudates. J Food Process Technol 9: 713. doi: 10.4172/2157-7110.1000713

Page 9 of 9

evaluation of a nutritionally balanced gluten free extruded snack. J Food Eng 75: 469-472.

7. Fan JM (1996) The effect of sugars on the extrusion of maize grits: I. The role of glass transition in determining product density and shape. Int J Food Sci Technol 31: 55-65.

8. Stojceska V, Ainsworth P, Plunkett A, Ilbanoglu E, Ilbanoglu S (2009) Cauliflower by-product as a new source of dietary fibre, antioxidant and proteins in cereal based ready to eat expanded snacks. J Food Eng 87: 554-563.

9. Montgomery DC (2001) Design and analysis of experiments. Wiley, New York, USA pp: $416-419$.

10. Gropper M, Kokini S (2002) Effect of specific mechanical energy on properties of extruded protein starch mixtures. Cereal Chem 79: 429-433.
11. Shivani P, Baljit S, Savita S, Vandana S, Smita S (2013) Optimization of extrusion processing conditions for preparation of an instant grain base for use in weaning foods. Int J Eng Res Appl 5: 1040-1049.

12. Omohimi Cl, Sobukola OP, Sarafadeen KO, Sanni LO (2013) Effect of process parameters on the proximate composition, functional and sensory properties. World Acad Sci Eng Technol 5: 04-24.

13. Vilma N, Tomas M, Grazina J, Loreta P (2008) The effect of extrusion conditions and cereal types on the functional properties of extrudates as fermentation media. Foodbalt 19: 60-63.

14. Illo L, Berhofer F (1999) Extrusion cooking of rice flour and amaranth blend Lebensm Wiss U Techno 32: 79-88.

15. Guy R (2001) Extrusion cooking: Technologies and application. Woodhead publishing Ltd, Cambridge, USA. pp: 3-5. 